\title{
Entry and Bidding in Common and Private Value Auctions with an Unknown Number of Rivals
}

\author{
Dakshina G. De Silva • Thomas D. Jeitschko • \\ Georgia Kosmopoulou
}

Published online: 13 October 2009

(C) Springer Science+Business Media, LLC. 2009

\begin{abstract}
In many procurement auctions bidders do not know how many rivals they face at the time that they incur the cost of preparing their bids. We show in a theoretical model that regardless of whether the procurement is characterized by private or by common values an increase in the potential number of bidders may lead to higher procurement costs. This raises potential policy questions of whether and how entry should be encouraged or limited in public procurement auctions. We use evidence from auctions of construction contracts to estimate the effect of an increase in the pool of potential bidders on entry and auction prices when entry and bidding decisions are made sequentially with no knowledge of the number or identity of the actual competitors.
\end{abstract}

Keywords Bid preparation costs · Common values · Endogenous entry · Private values $\cdot$ Procurement auctions

JEL Classification $\mathrm{H} 4 \cdot \mathrm{H} 57 \cdot \mathrm{D} 44$

D. G. De Silva (西)

Department of Economics and Geography, Texas Tech University, Lubbock, TX 79409-1014, USA

e-mail: dakshina.de-silva@ttu.edu

T. D. Jeitschko

Department of Economics, Michigan State University, East Lansing, MI 48824, USA

e-mail: jeitschk@msu.edu

G. Kosmopoulou

Department of Economics, University of Oklahoma, Norman, OK 73019, USA

e-mail: georgiak@ou.edu 


\section{Introduction}

In many government procurement auctions bidders must prepare their bids at a cost and in ignorance of the actual competition that they face. We provide a characterization of optimal bidding in a model that has both the common and the private values auctions as polar cases under the assumption that the number of bidders is endogenously determined. The known number of plan holders (i.e., the set of potential bidders) trade off the likely auction payoffs from participating with the bid preparation costs incurred in the process of bidding.

We assume that bid preparation costs are incurred in the process of the bidders' value determinations, so that the entry decision is made prior to determining a particular bid. This essentially yields a sequential decision process for the bidders-first, whether or not to enter, and second, how high to bid upon entry. We examine how these decisions are affected by both the nature of the project (private vs. common value) and the number of potential bidders. This two-step procedure generates theoretical considerations that we examine with actual data from procurement auctions.

The problem of endogenous entry in the presence of an unknown number of rivals has been studied elsewhere in the literature. Harstad (1990) considers a common value auction, whereas Engelbrecht-Wiggans (1987), Deltas and Jeitschko (2007), and Moreno and Wooders (2008) consider the independent private values (IPV) setting. Levin and Smith (1994) study a general framework and assume a stochastic number of bidders at the entry stage. Bidders learn the number of competitors prior to bidding. Menezes and Monteiro (2000) assume that the bidders learn their values before they incur the bid preparation cost. Marmer et al. (2007) consider a model within the IPV setting in which bidders receive information at the entry stage that is imperfectly correlated with their valuations; they pay a bid preparation cost to learn the actual private cost of the contract and bid without knowing the number of competitors.

Li and Zheng (2008) is most closely related to our work, as they have the same informational assumptions as we do; however, they restrict attention to the IPV model. Indeed, our main results for the polar case of private values is analogous to their findings, even though there is some variation in the modeling assumption even for the private values case. Moreover, our framework incorporates a range of different assumptions on bidders' valuations and allows us to provide a comparison across cases.

Using road construction auction data from the Texas Department of Transportation (TxDOT), we examine a two-step process of 'entry' and 'bidding' for plan holders in independent private value and common value auctions. We show that an increase in the number of potential competitors has a more significant effect in independent private value auctions compared to auctions with large common value components. Whereas the number of potential bidders has an effect on the probability to submit a bid, most of the effect of the number of potential bidders on the bid levels is through the competitive effect. The entry decision may have less to do with the number of competitors and more with project characteristics and potential synergies between projects that are being auctioned off. 
The model and the main theoretical findings of interest are presented in Sect. 2. A description of the data set used is given in Sect. 3 followed by the empirical analysis in Sect. 4. We conclude with policy implications and possible concerns for the organization of procurement auctions in Sect. 5.

\section{Model}

Consider the set of potential bidders for construction projects auctioned off by the government. These are the firms that are pre-approved by the contracting agency for bidding in procurement auctions. Periodically, the government has projects to be completed that are allocated by means of procurement auctions. In a first step, the agency draws up plans that give the specifics of a project. While the general class of the project is known to bidders (e.g., road resurfacing, bridge work, etc.), the specifics are discovered only by obtaining the plans. Regularly, not all preapproved firms secure a copy of these plans. We denote the group that do by $\mathcal{N}$, with $\mathcal{N}=\{1, \ldots, N\}$, and refer to them as the plan holders. Assume that $\mathcal{N}$ is determined exogenously.

Upon obtaining a plan for project $j$, a plan holder determines (observes) his individual bid-preparation (drafting) cost, $d_{i j}$, which are distributed i.i.d. according to the strictly increasing function $F_{d_{j}}$ on $[0, \infty)$. On the basis of the bid preparation cost a bidder decides whether or not to become active and enter a bid in the auction. We denote by $\mathcal{A} \subseteq \mathcal{N}$ the number of active bidders, with $\mathcal{A}=\{1, \ldots, A\}$.

While the number of plan holders $N$ is known to all bidders, the number of bidders, $A$, is not so that bids are prepared under "number uncertainty." However, the equilibrium is derived by first determining the optimal strategy when the number of rivals is known (i.e., for given $A$ ) and then the optimal strategies for the case of number uncertainty (known $N$, but unknown $A$ ) are compiled from the strategies with a known number of rival bidders. We therefore proceed under the assumption that a bidder's number of rivals, $A-1$ is known to the bidder and first determine the equilibrium bid strategies under this assumption-thereafter dropping this assumption in order to derive the equilibrium for the model in which bidders are uncertain about the number of rivals that they face at the bidding stage.

In the process of preparing a bid, bidders obtain information on their costs for completing the project. The costs of completing a project are a composite of private cost characteristics (e.g., one's own capacity utilization, equipment) and common cost elements (e.g., costs of materials, or costs of subcontracting). Specifically, let a firm's costs be $\gamma c_{i j}+(1-\gamma) K_{j}$, where $\gamma c_{i j}$ denotes the firm's private cost component, $(1-\gamma) K_{j}$ denotes the cost component that is common to all firms, and $\gamma \in[0,1]$ denotes the weight of private and common cost components in the overall cost to the firm.

Bidders' private cost components are derived from i.i.d. draws $c_{i j}$ from the logconcave distribution $F_{c_{j}}$ on $\left[\underline{c}_{j}, \bar{c}_{j}\right]$. Bidders observe their own private cost components and know the distribution $F_{c_{j}}$. Bidders also observe a signal on the common cost component. Specifically, each bidder privately observes an i.i.d. draw $k_{i j}$ from 
the commonly known log-concave distribution $F_{k_{j}}$ on $\left[\underline{k}_{j}, \bar{k}_{j}\right]$. The common cost component then results from $K_{j}=\frac{1}{A} \sum_{i} k_{i j}$, where $A$ is the number of (active) bidders. ${ }^{1}$

The auction format is a standard lowest-price closed-bid procurement auction in which bids above the highest possible cost are rejected. Letting $E$ denote the expectations operator for the common cost component, a bidder who wins a contract with bid $b_{i j}$ has an expected (continuation) payoff (gross of bid preparation costs) of $b_{i j}-\gamma c_{i j}-$ $E\left[(1-\gamma) K_{j}\right]=b_{i j}-\gamma c_{i j}-(1-\gamma) \frac{1}{A} E\left[\sum_{m \in \mathcal{A}} k_{m j}\right]=b_{i j}-s_{i j}-(1-\gamma) \frac{A-1}{A} E k_{j}$; where $s_{i j}:=\gamma c_{i j}+(1-\gamma) \frac{1}{A} k_{i j}$ denotes a bidder's "type" for a given number of rivals $A$.

Notice first that a bidder's payoff is strictly monotone in his type $s_{i j}$. Second, since $f_{c_{j}}(x)$ and $f_{k_{j}}(x)$ are log-concave, so are $\tilde{f}_{c_{j}}(x):=f_{c_{j}}(\gamma x)$ and $\tilde{f}_{k_{j}}(x):=$ $f_{k_{j}}((1-\gamma) x / A)$. Moreover, since $c_{j}$ and $k_{j}$ are independent, the convolution of their distributions is also log-concave. Thus, the distribution of types for a given $A$ denoted by $F_{s_{j}^{A}}$ on $\left[\underline{s}_{j}^{A}, \bar{s}_{j}^{A}\right]:=\left[\gamma \underline{c}_{j}+(1-\gamma) \frac{1}{A} \underline{k}_{j}, \gamma \bar{c}_{j}+(1-\gamma) \frac{1}{A} \bar{k}_{j}\right]$, is log-concave. In sum, the bidders' two dimensional signals on costs can be aggregated into the onedimensional type $s$ which is assured to be monotone in bidders' values of winning the contract and of which the distribution is log-concave. Hence, the standard methodology for deriving the equilibrium bid function in IPV auctions for a known number of rivals can be used. That is, bidders place bids that exceed their expected costs by the expected cost difference to the next-lowest-cost bidder, assuming that they themselves have the lowest overall costs.

Formally, the symmetric equilibrium bidding function for a first-(i.e., lowest-)price sealed-bid auction when the number of rivals $(A-1)$ is known is given by:

$$
\begin{aligned}
B_{j}(s \mid A)= & E\left[\gamma c_{i j}+(1-\gamma) K_{j} \mid s_{i j}=\min _{m \in \mathcal{A}} s_{m j}=s ; A\right] \\
& +E\left[\min _{m \neq i, m \in \mathcal{A}} s_{m j}-\min _{m \in \mathcal{A}} s_{m j} \mid s_{i j}=\min _{m \in \mathcal{A}} s_{m j}=s ; A\right],
\end{aligned}
$$

with bids restricted to be below $\gamma \bar{c}_{j}+(1-\gamma) \bar{k}_{j}$.

The first term in the bid function is the agent's expected cost of completing the project, assuming that he has the lowest cost and assuming that there are $A$ rivals. The second term in the bid function gives the amount by which bids are increased above cost estimates, which is the expected difference in costs between the bidder and the next lowest-cost bidder, given the same conditioning.

Having established the bidding procedure when the number of rivals is known, one can consider the problem faced by a bidder with an unknown number of rivals. A critical result established in Goeree and Offerman (2003) (i.e., Proposition 4) is that the particular aggregation of each bidders' two signals into one-dimensional types not only allows for the derivation of the equilibrium in the lowest price auction using

\footnotetext{
1 This set-up is very similar to Goeree and Offerman (2003) which serves as a basis for the subsequent derivation of the equilibrium bid function with a known number of rivals.
} 
standard methodology, but also results in revenue (and hence payoff) equivalence across auction formats. This is convenient, since Krishna (2002) demonstrates how payoff equivalence is used to derive the optimal bidding strategies for the auction with an uncertain number of rivals as a compilation of the strategies used for the underlying cases with known numbers of rivals (Krishna 2002, pp. 35-36). Specifically, the equilibrium bid function is a weighted average of the bid functions used with different (known) numbers of rivals. To this end, define

$$
p(A \mid N)=\operatorname{Pr}\{A \text { active bidders, given } N \text { plan holders }\}
$$

and let

$$
\left(1-F_{s_{j}^{A}}(y)\right)^{(A-1)}=\operatorname{Pr}\left\{\text { smallest of } A-1 \text { draws from } F_{s_{j}^{A}} \text { is greater than } y\right\},
$$

with $\left(1-F_{s_{j}^{A}}(y)\right)^{(0)}=1$. Then the symmetric equilibrium bidding function for the first (i.e., lowest) price auction with $N$ plan holders and unknown number of active bidders $A$ is given by

$$
B_{j}(s \mid N)=\sum_{A=1}^{N} \frac{p(A \mid N)\left(1-F_{s_{j}^{A}}(s)\right)^{(A-1)}}{\sum_{A=1}^{N} p(A \mid N)\left(1-F_{s_{j}^{A}}(s)\right)^{(A-1)}} B_{j}(s \mid A) .
$$

In order to complete the analysis, the equilibrium probabilities of entry, $p(A \mid N)$, remain to be determined. Individual bidders are willing to incur their bid-preparation costs of $d_{i j}$ provided that their expected earnings in the auction are sufficient to cover these costs. The expected earnings of the winner of the auction is the difference in cost-types between the lowest and second-lowest types when there are $A$ active bidders. Clearly a bidder's ex ante expectation of this is subject to the number of bidders who enter the auction. Moreover, since bidders make the entry decision prior to knowing their type $s_{i j}$, the expected payoff of entering is the same for all plan holders, although their bid preparation costs are not. Thus, letting $S_{(l: A)}^{j}$ denote the lth (lowest) order statistic from $A$ draws from $F_{s_{j}^{A}}$ (with $S_{(l: A)}^{j}:=\bar{s}_{j}$ whenever $l>A$ ), a bidder's expected payoff from participating in an auction with $A$ bidders, before knowing his type is

$$
\pi_{i j \mid A}=\frac{E\left[S_{(2: A)}^{j}-S_{(1: A)}^{j}\right]}{A}
$$

and given the different probabilities of numbers of (active) bidders, the ex ante expected payoff is given by

$$
\pi_{i j}=\sum_{A=1}^{N} p(A \mid N) \frac{E\left[S_{(2: A)}^{j}-S_{(1: A)}^{j}\right]}{A}
$$


Since bidders' bid preparation costs, $d_{i j}$, are distributed according to the function $F_{d_{j}}$ on $[0, \infty)$, for arbitrary cutoff $x$, the probability that a bidder faces exactly $A-1$ of $N-1$ rival plan holders that have bid preparation costs below $x$ is given by

$$
p(A \mid x, N)=\left(\begin{array}{c}
N-1 \\
A-1
\end{array}\right) F_{d_{j}}(x)^{A-1}\left(1-F_{d_{j}}(x)\right)^{N-A} .
$$

In equilibrium, all bidders with bid preparation costs lower than the expected auction payoff enter the auction. Thus, the threshold bid-preparation cost, $d_{i j}^{*}$, that determines the bidder who is exactly indifferent between staying out of the auction and entering the auction (thus incurring the bid preparation cost of $d_{i j}^{*}$ ) is uniquely determined by

$$
d_{i j}^{*}=\sum_{A=1}^{N}\left(\begin{array}{c}
N-1 \\
A-1
\end{array}\right) F_{d_{j}}\left(d_{i j}^{*}\right)^{A-1}\left(1-F_{d_{j}}\left(d_{i j}^{*}\right)\right)^{N-A} \frac{E\left[S_{(2: A)}^{j}-S_{(1: A)}^{j}\right]}{A} .
$$

Taking the above results together, one obtains the joint conditions for the unique symmetric equilibrium entry and bidding strategies:

Proposition 1 (Equilibrium Entry and Bidding) In the unique symmetric equilibrium, bidders with bid preparation costs below $d_{i j}^{*}$ enter the auction and upon observing their cost signals $c_{i j}$ and $k_{i j}$ bid according to the function

$$
\begin{aligned}
B_{j}\left(c_{i j}, k_{i j} \mid N\right)= & \sum_{A=1}^{N} \frac{p\left(A \mid d_{i j}^{*}, N\right)\left(1-F_{s_{j}^{A}}\left(s_{i j}^{A}\right)\right)^{(A-1)}}{\sum_{A=1}^{N} p\left(A \mid d_{i j}^{*}, N\right)\left(1-F_{s_{j}^{A}}\left(s_{i j}^{A}\right)\right)^{(A-1)}} \\
& \times E\left[\gamma c_{i j}+(1-\gamma) K_{j}+\min _{l} s_{l j}^{A}-\min _{l \neq i} s_{l j}^{A} \mid s_{i j}^{A}=\min _{l \in \mathcal{A}} s_{l j}^{A}\right],
\end{aligned}
$$

where $s_{i j}^{A}=\gamma c_{i j}+(1-\gamma) k_{i j} / A$; and $d_{i j}^{*}$ is implicitly given by Eq. 3 .

Proof The construction of the equilibrium follows from the above derivations. Uniqueness of the entry threshold follows from the fact that both sides of Eq. 3 are continuous in $d_{i j}$, and the left-hand-side is increasing, whereas the right-hand-side is decreasing. To see the latter, note that the bidder's expected payoff as a function of the number of active bidders (Eq. 1) is strictly decreasing in $A$. This is the second term in the product on the right-hand-side of Eq. 3. The first term in the product on the right-hand-side of Eq. 3 is the distribution of the number of active bidders given by Eq. 2. An increase in $d_{i j}$ strictly increases $F_{d_{j}}\left(d_{i j}\right)$ (since $F_{d_{j}}$ is strictly increasing), which induces a first-order-stochastic-dominance shift in the distribution of bidders (see, Wolfstetter 1999, Lemma 8.3, p. 223), hence increasing the probability of obtaining a lower payoff due to greater participation. ${ }^{2}$

\footnotetext{
${ }^{2}$ It is noteworthy that although Moreno and Wooders (2008) consider only private values auctions, the proof of uniqueness of their symmetric equilibrium applies here as well, since our framework maps into the general pay-off structure used in the proofs there.
} 
We now consider the bidding and entry equilibrium for independent private values and common values separately. Our main concern is how the number of plan holders affects the bidding behavior in the auction.

In general, this relationship is given by

$$
\frac{d B}{d N}=\frac{\partial B}{\partial N}+\frac{\partial B}{\partial p} \frac{\partial p}{\partial d_{i j}^{*}} \frac{\partial d_{i j}^{*}}{\partial N} ;
$$

where, following Li and Zheng (2008), we refer to the first part as the "competition effect," which captures the effect of increased (potential) competition on bidding behavior, for given entry probabilities, and we refer to the second effect as the "entry effect," which captures that incurring the expense of bid preparations becomes less attractive the smaller is the expected payoff from participating in the auction.

Lemma 1 (Competition Effect) The partial effect of the number of plan holders on equilibrium bids is negative in the pure private values setting, i.e.,

$$
\frac{\partial B}{\partial N}<0
$$

whereas in the pure common values setting it depends on the distribution and need not be monotone.

Proof Recall that the bid function is a weighted average of the bid functions that are used when the number of rivals is known, as given above. Notice that in the private values framework (i.e., $\gamma=1$ ) bids in these latter functions are decreasing in $A$. Since an increase in $N$ leads to an increase in the expected number of bidders $A$ in the sense of first-order stochastic dominance (also Wolfstetter 1999, Lemma 8.3, p. 223), the result follows. The fact that the sign depends on the distributional assumptions and may not be monotone for the case of common values is well known for the bidding functions with known rivals (see, e.g., Wilson 1992), and carries over to this setting as well.

The latter part of the Lemma draws an apparent clear contrast between private and common value auctions. Moreover, Wilson's (1992) work on normal and lognormal distributions suggests that bids are decreasing in the number of plan holders for a small $N$, but become increasing for larger $N$.

As for the entry effect, ambiguity persists for the case of common value auctions, but not for private value auctions. Formally,

Lemma 2 (Entry Effect) The partial effect of endogenous entry on bidding is positive in the pure private values case, i.e.,

$$
\frac{\partial B}{\partial p} \frac{\partial p}{\partial d_{i j}^{*}} \frac{\partial d_{i j}^{*}}{\partial N}>0,
$$

whereas in the pure common values setting it is ambiguous. 
Proof For both cases - private and common values - the implicit partial derivative of Eq. 3 with respect to entry can be shown to be negative, $\frac{\partial d_{i j}^{*}}{\partial N}<0$, since expected payoffs are decreasing in bidder participation (see, e.g., Deltas and Jeitschko 2007). As for the sign of $\frac{\partial B}{\partial p} \frac{\partial p}{\partial d_{i j}^{*}}$, the proof of Lemma 1 follows mutatis mutandis, sinceas referenced in the proof to Proposition $1-p$ increases in the sense of first order stochastic dominance also for the case of changes in $A$.

The theoretical results in Lemmata 1 and 2 suggest that the effects of potential entry are sensitive to and may differ substantially between private and common cost projects. In the private cost setting the effects are unambiguous, but operate in opposite directions, whereas in the common cost case, the competitive effect is non-monotonic and the entry effect can be ambiguous. As a result, the decision to encourage or discourage entry may be based on close consideration of the characteristics of the projects auctioned off. The empirical analysis of the next section helps in shedding some light on these issues.

\section{Data}

\subsection{Data Description}

We utilize data from the Texas Department of Transportation (TxDOT) to examine bidding behavior under the assumption that the number of bidders is endogenously determined. The data used in this study comprise information on asphalt and bridge construction projects auctioned by TxDOT from August 1998 to August 2007. Projects are auctioned each month, in a first-price sealed-bid format wherein the lowest bidder is awarded the contract. For each project, there is information on the plan holders (contractors that hold plans), the bids submitted by each firm if it bid, the winning bid, and the winning firm.

It is important to note that before a bidder may submit a bid on a construction or maintenance project, the Department of Transportation requires that the bidder be qualified. ${ }^{3}$ The list of plan holders identifies the potential prequalified competitors for a given project. The plan holder list is updated daily and is public information and available to all bidders prior to the auction letting. The plans are obtained free of charge from the TxDOT. These give the location, a detailed description of the tasks that can relay complexity, the estimated time to completion and, most importantly, the detailed engineering cost estimate (ECE) for each project component. At this stage, potential competitors might learn about specialized input required in the process that can affect the level of bids or the number of actual bidders. We view $N$ as an exogenous variable.

\footnotetext{
3 Pre-qualification involves bidders' submission of certified financial statements to the TxDOT and is related to the level of working capital available to the potential bidder as well as its history of successful completion of projects. The resultant evaluation is used to determine the size of projects that a firm can bid on. Firms can be disqualified and 'black listed' at any time if they fail to complete contracts successfully. More information about pre-qualification can be obtained at http://www.dot.state.tx.us/business.
} 
Each project has many bid components. These bid components are classified in categories identified by the 2004 TxDOT Standard Specifications (TSS). ${ }^{4}$ We sum the total dollar value of the bid components in each category and calculate its share as a ratio of ECE. Suppose that for a given project the highest share belongs to the asphalt component category. In this case, we identify that project as an asphalt project. A similar method is used in categorizing bridge work.

The data set is a panel data set where an observation is a firm that held a plan and possibly submitted a bid for a given project. Note that, firms may place multiple bids for multiple projects in a month or may not bid at all, and therefore, the panel structure is unbalanced.

We discuss the details of variable construction below. In this study, we utilize the bidding data of firms that participated in auctions held from August 1998 to December 1999 to create bidding and capacity utilization histories. Note that, in the regression analysis we use data from January 2000 to August 2007. Our interest is to study bidding behavior separately in those auctions that have predominantly common and private cost components when the participation decision is endogenous. As in Hong and Shum (2002) and De Silva et al. (2008), we categorize asphalt projects as independent private value auctions and bridge work as projects with large common value components. The reason is that asphalt projects are generally straightforward, requiring a contractor to lay down asphalt across a specific road surface to a certain thickness. Compared to asphalt, the costs associated with bridge work are often more uncertain. Note that, as each bridge is different, bridge construction projects, will differ in complexity. In our analysis of bridge projects, we use only auctions with at least $50 \%$ share on bridge work. We also restrict attention to asphalt maintenance projects with at least $50 \%$ asphalt share and bridge, earth and subgrade components less than 5\% to limit uncertainty in the performance of a task.

Table 1 provides descriptive statistics for the data set. Due to the volume of auctions, TxDOT conducts two sessions of bid letting within each month, typically taking place on two consecutive days. We present statistics for the second session separately.

When considering asphalt projects, we observe that there were 1,216 awarded auctions with on average a little over six plan holders per auction and fewer than four bidders per auction. ${ }^{5}$ The average relative bid for asphalt projects was 1.008 and the average relative winning bid was .938 . Also, we observe that the average number of bid items was about 33 and the average asphalt-related work share compared to the ECE was .786.

When considering bridge work projects we observe that there were 1,112 awarded auctions with an average number of plan holders between eight and nine, yielding just about five bids per auction. The average relative bid for bridge projects was 1.163 and the average relative winning bid was 1.015. The average number of bid items was about 62 for bridge projects and the bridge related work share compared to ECE was .657.

In the sample of second sessions, the values are similar to the full sample values.

\footnotetext{
4 TxDOT Specifications. http://www.dot.state.tx.us/business/specifications.htm.

5 In this auction setting there is no explicit reserve price. Generally, however, the ECE is a basis for rejection of a project. Based on this the state may reject bids as unbalanced but the data reveal that only eight out 1,224 asphalt auctions and five out of 1,117 bridge projects were rejected in the sample of analysis.
} 
Table 1 Summary statistics

\begin{tabular}{llllll}
\hline Variables & \multicolumn{2}{l}{ Asphalt projects } & & \multicolumn{2}{l}{ Bridge projects } \\
\cline { 2 - 3 } \cline { 5 - 6 } & Full sample & Second session & & Full sample & Second session \\
\hline Number of auctions & 1,224 & 603 & & 1,117 & 505 \\
Number of awarded auctions & 1,216 & 600 & & 1,112 & 503 \\
Average number of plan holders & $6.077(2.547)$ & $6.212(2.591)$ & & $8.646(3.507)$ & $8.431(3.376)$ \\
Average number of bidders & $3.745(1.736)$ & $3.733(1.758)$ & & $5.151(2.211)$ & $4.932(1.952)$ \\
Average relative bid & $1.008(.175)$ & $1.004(.178)$ & & $1.163(.282)$ & $1.160(.253)$ \\
Average relative winning bid & $.938(.150)$ & $.939(.156)$ & & $1.015(.242)$ & $1.017(.199)$ \\
Average engineering & $\$ 3.163(3.040)$ & $\$ 3.289(2.866)$ & & $\$ 4.057(15.600)$ & $\$ 3.250(9.851)$ \\
$\quad \begin{array}{l}\text { estimate } \\
\text { Asphalt work bid items share }\end{array}$ & $.786(.079)$ & $.786(.079)$ & & $.039(.051)$ & $.043(.053)$ \\
Bridge work bid items share & $.004(.010)$ & $.005(.011)$ & & $.657(.097)$ & $.649(.095)$ \\
Average number of bid & $33.143(19.456)$ & $33.252(18.238)$ & & $62.150(68.660)$ & $62.023(57.152)$ \\
components in a project & & & & & \\
\hline
\end{tabular}

${ }^{a}$ In millions of dollars. Standard deviations are in parentheses

\subsection{Variable Definitions}

In our analysis we use a bid dummy to summarize bidder participation patterns and the log of bids to summarize bidding patterns. The independent variables can be classified into four main groups; namely, auction characteristics, bidder characteristics, rival characteristics, and business environment characteristics. Construction of these variables is given in Table 5 in the Appendix. There are 13 auction-level variables- the number of plan holders, expected number of bidders, ECE, seven project share variables, and the number of bid items. The number of plan holders and expected number of bidders control for differences in competition in auctions and the project type shares control for the fact that we observe differences in bidding across project categories. The engineering cost estimates are constructed by the state by pricing each bid item outlined in the design and then deriving an overall cost estimate for the project. The engineering cost estimate is used to control for project-specific differences in cost. We also use the number of bid items in a project to control for the complexity of the project and the number of days to complete the project.

With respect to bidders' own characteristics, in addition to firm fixed effects, five measures are used to control for bidder cost heterogeneities. We use a dummy variable to identify when a bidder is bidding in the same county where the firm has an ongoing project to identify the potential for synergies. A past winner with an ongoing project in a specific county may be able to extract cost complementarities by bidding in similar projects in the same county. A similar approach has been used by De Silva (2005). We use a firm's difference between its current capacity utilization rate and its average capacity utilization rate to explore excessive commitment in capacity. We also use the distance to a project.

As mentioned earlier, all auctions taking place in a month are offered in two sessions. Bids are placed separately on each contract and all bids submitted within a session are 
opened simultaneously. Synergies may play an important role in these auctions, and there is evidence of bidding variation in the second session of a month due to a win or loss in the first session. Therefore, we use the dummy variables "bidders with potential synergies" and "bidders with no potential synergies" to capture first session winners and losers. Note that at the entry stage bidders use all past information and the entry decision is made for all upcoming auctions at the same time. When an entry decision is made, the bidder does not know the outcome of the auctions in the first upcoming session but knows the outcome of auctions from previous months. Therefore, we have used these synergy variables only in the bidding equation as in De Silva et al. (2002) and use only second day auctions in order to exploit the difference in information available at the entry and bidding stages and identify appropriately the entry equation.

When considering rivals' characteristics we construct four variables: First, we utilize past information on rivals' bidding and construct the average bidding percentage of all rival plan holders in an auction. Also, we construct another variable: the average winning percentage of all rival plan holders in an auction using past histories. These variables measure rivals' toughness. If firms face a set of tough rivals, we expect them to bid more aggressively. Next, we include the rivals' minimum distance to the project and the minimum backlog of rivals. These variables are also used to control for rival cost heterogeneity and are similar to variables used by Bajari and Ye (2003). ${ }^{6}$

Finally, other than the ECE information, it is important to control for factors that change over time. Hence, we use three variables that control for the business environment. These are: (1) the monthly unemployment rate, (2) the monthly variation in the amount of projects being let, and (3) the monthly building permits. The variable on monthly variation in the amount of projects being let measures the real volume of projects auctioned off each month. The aggregate real volume of projects auctioned off in a month varies across seasons. This may affect bidding behavior of firms as the relative real volume of projects being let changes. Summary statistics of all the regression variables are presented in Table 2.

\section{Empirical Analysis}

In this section, we examine bidding behavior under the assumption that the number of bidders is endogenously determined as (the known number of) plan holders decide on entry based on a comparison of the expected payoffs from participation at the auction and the bid preparation costs incurred prior to bidding. This essentially yields a sequential decision process for the bidders-first they decide whether to enter, and then how low to bid upon entry. We investigate empirically differences in the entry and bidding behavior across different types of auctions and focus on the impact of the exogenous number of plan holders upon a bid consisting of a direct and an indirect effect through the number of actual participants. At the same time, we use variables that identify potential synergies across projects and include workload, distance effects, and rival history. This two-step empirical procedure is used to shed light on the theoretical results in Sect. 2.

\footnotetext{
6 See also Jofre-Bonet and Pesendorfer (2003) and De Silva et al. (2008, 2009, 2003, 2005).
} 
Table 2 Summary statistics of regression variables

\begin{tabular}{|c|c|c|c|c|}
\hline \multirow[t]{2}{*}{ Variables } & \multicolumn{2}{|c|}{ Asphalt projects } & \multicolumn{2}{|c|}{ Bridge projects } \\
\hline & Mean & SD & Mean & $\mathrm{SD}$ \\
\hline $\begin{array}{l}\text { Probability of submitting a } \\
\text { bid }\end{array}$ & 616 & $(.486)$ & .596 & $(.491)$ \\
\hline Log of bids & 14.511 & $(.971)$ & 13.800 & $(1.345)$ \\
\hline Log number of plan holders & 2.046 & $(.339)$ & 2.346 & $(.346)$ \\
\hline Log number of bidders & 1.593 & $(.358)$ & 1.847 & $(.362)$ \\
\hline $\begin{array}{l}\text { Log expected number of } \\
\text { bidders }\end{array}$ & 1.621 & $(.287)$ & 1.857 & $(.316)$ \\
\hline $\log$ of ECE & 14.551 & $(1.009)$ & 13.647 & $(1.427)$ \\
\hline Asphalt work share of ECE & .784 & $(.083)$ & .037 & $(.050)$ \\
\hline Bridge workshare of ECE & .004 & $(.010)$ & .659 & $(.099)$ \\
\hline Earth work share of ECE & .004 & $(.014)$ & .073 & $(.055)$ \\
\hline $\begin{array}{l}\text { Maintenance and } \\
\text { miscellaneous share of ECE }\end{array}$ & .001 & $(.012)$ & .0027 & $(.017)$ \\
\hline Subgrade share of ECE & .002 & $(.007)$ & .0252 & $(.030)$ \\
\hline Traffic share of ECE & .094 & $(.073)$ & .015 & $(.026)$ \\
\hline $\begin{array}{l}\text { Log of number of bid } \\
\text { components }\end{array}$ & 3.366 & $(.594)$ & 3.772 & $(.788)$ \\
\hline $\begin{array}{l}\text { Log of number of days to } \\
\text { complete the project }\end{array}$ & 4.181 & $(.654)$ & 4.715 & $(.909)$ \\
\hline $\begin{array}{l}\text { Difference between firm's } \\
\text { current and average } \\
\text { utilization }\end{array}$ & -.000 & $(.196)$ & .000 & $(.217)$ \\
\hline Log of distance to project & 4.498 & $(1.180)$ & 4.273 & $(1.084)$ \\
\hline $\begin{array}{l}\text { Bidders with ongoing projects } \\
\text { in the same project county }\end{array}$ & .200 & $(.400)$ & .173 & $(.378)$ \\
\hline $\begin{array}{l}\text { Bidder with potential } \\
\text { synergies }\end{array}$ & .137 & $(.390)$ & .083 & $(.276)$ \\
\hline $\begin{array}{l}\text { Bidder with no potential } \\
\text { synergies }\end{array}$ & .187 & $(.104)$ & .158 & $(.364)$ \\
\hline $\begin{array}{l}\text { Rival's past bidding to plan } \\
\text { holder ratio }\end{array}$ & .610 & $(.104)$ & .573 & $(.111)$ \\
\hline $\begin{array}{l}\text { Rival's past winning to plan } \\
\text { holder ratio }\end{array}$ & .157 & $(.058)$ & .123 & $(.036)$ \\
\hline $\begin{array}{l}\text { Log of rival's minimum } \\
\text { distance to the project } \\
\text { location }\end{array}$ & 3.486 & $(1.045)$ & 3.059 & (1.005) \\
\hline $\begin{array}{l}\text { Log of rival's minimum } \\
\text { backlog }\end{array}$ & 6.167 & $(6.939)$ & 4.984 & $(6.099)$ \\
\hline $\begin{array}{l}\text { Seasonally unadjusted } \\
\text { unemployment rate }\end{array}$ & 5.443 & $(.869)$ & 5.423 & $(.883)$ \\
\hline $\begin{array}{l}\text { Three month average of the } \\
\text { real volume of projects }\end{array}$ & .979 & $(.277)$ & 1.042 & $(.308)$ \\
\hline $\begin{array}{l}\text { Three month average of the } \\
\text { number of building permits }\end{array}$ & .994 & $(.190)$ & 1.041 & $(.188)$ \\
\hline
\end{tabular}


Li and Zheng (2008) consider entry and competitive effects in a set of first-price auctions of mowing contracts procured by the state of Texas. Their theory examines entry and competitive effects in a private value framework. They employ a semi-parametric Bayesian method to estimate a structural model. Their choice of method calls for the use of a smaller set of contracts that are less complex. There is no use of capacity utilization, synergies, and rival history.

In our empirical analysis, first we want to test if there is an inverse relationship between the entry probability $q$ and the number of potential bidders $N$ to establish an implicit link of the bidding function to the number of potential bidders through the entry decision.

We consider a model estimated in two stages: In the first stage, entry probabilities are estimated using a probit model. The basic structure of the entry decision model is as follows:

$$
\operatorname{Pr}(h=1 \mid z)=\Phi\left(z^{\prime} \varsigma\right)
$$

The variable $h$ is the bid dummy that takes on two values: the value 1 when a bidder submits a bid and 0 when they are only plan holders. The $z$ s are all entry cost variables, which are: number of plan holders, ECE, number of project components, days to complete the project, a dummy variable identifying large firms, capacity utilization, distance to the project, bidding in a county with ongoing projects, rivals' past bidding to plan holder ratio, unemployment rate, volume of projects, and number of building permits. All regressions include a constant term, 11 monthly and seven annual dummy variables. In the full sample, we have included five project component share variables.

In the second stage, the basic structure of the equilibrium bid model is as follows:

$$
y_{i a t}=\phi_{i}+x_{i a t}^{\prime} \beta+\varepsilon_{i a t},
$$

where the unit of observation is firm $i$ bidding in auction $a$ at time $t$ and $y_{i a t}$ is that firm's bid. All models include bidder fixed effects $\left(\phi_{i}\right)$ as well as a set of controls $\left(x_{i a t}\right)$ for bidder, rival, auction, and business conditions variables. The two specifications differ in a number of variables. The entry stage incorporates general information on projects and rivals while the bidding stage incorporates more detailed information available at the time of bidding. For example, at the entry stage we consider if the project is in a county where the firm has another ongoing project while at the bidding stage we consider the bidder's potential to gain from synergies based on recent wins or losses and specific starting dates of complementary projects. Some of that information is not available to the firms at the entry stage. ${ }^{7}$ Better local knowledge about available resources and familiarity with topography play a major factor in the entry decision. Potential synergies in addition can create an advantage to a firm at the bidding stage.

\footnotetext{
7 As an example, take the fact that the State has two auctions sessions within a given month, taking place on two consecutive days. The winner and the losers of an early auction may bid differently in a later auction, based on potential synergies.
} 
Table 3 presents the entry decision using probit analysis. The first column is for asphalt projects and the second for bridge work projects. Since firms are observed repeatedly, the observations may not be independent. In this case standard errors can be underestimated ${ }^{8}$. Therefore, we report standard errors that are clustered by firms. It is clear from the probit results that there is an inverse relationship between the entry probability and the number of bidders. We observe that as the number of potential bidders or plan holders increases the probability of submitting a bid decreases both under private or common value uncertainty. This is part of the 'entry effect' identified in the theoretical section. It is also evident from the results that the potential for synergies and the size of a firm are key factors in making entry decisions. As the distance between project and firm location increases the probability of entering the auction decreases. However, if a bidder has an ongoing project in the same county, then the probability of participation increases implying the potential for synergies. The number of bid components affects the probability of submitting a bid in particular when considering asphalt projects. The number of bid components has a direct effect on the bid preparation cost which should be higher for more complex projects.

The estimates of the second stage bidding model are reported in the first part of Table 4 and discussed later in comparison with other alternative specifications. We estimate the bidding functions using the expected number of bidders from two different specifications in an attempt to capture the overall effect of the number of plan holders on the bid that include entry and competitive effects. Columns (1) and (3) use predicted number of bidders from the probit equation. Columns (2) and (4) use estimates from the expected number of bidders that are calculated using past histories. ${ }^{9}$ In the second stage, we use only the second-day auctions. Specifically, first session winners may adjust their bids in order to extract potential synergies, and similarly losers may bid aggressively to recover early losses. This information was not available at the entry stage. ${ }^{10}$

Our main interest is the in the coefficient of the log of the expected number of bidders. As can be seen in private value auctions (asphalt projects) the expected number of bidders has a negative effect on the bid level and in common value auctions (bridge work) its effect is ambiguous and insignificant. As theory predicts, in common value auctions, bidders make upward adjustments and we expect this to be smaller or even positive for large expected number of bidders due to the winner's curse effect. In the second stage, we use a firm level fixed effect regression controlling for firm specific

\footnotetext{
8 See Moulton (1990) for more details.

9 For each plan holder at at each point in time, we construct the ratio of their past number of bids to past number of plans held. This gives a probability of bidding for each plan holder. Therefore, for a given auction at a given time, we sum across these participation probabilities for all plan holders in an auction. This gives us our measure of the expected number of bidders. Since the identity of the plan holders is known to all potential bidders, an estimate of the expected number of bidders can be constructed by firms in such a way prior to the bid submission. This measure is similar to that used by Hendricks et al. (2003) and De Silva et al. (2008).

10 The two-stage analysis, using probit to determine entry, assumes that a bidder who incurs the bid preparation cost will not withdraw a bid in the event that his firm did not win a complementary project on the first day of bidding. A firm would rather adjust its bid to reflect this lack of synergy, an assumption that is not unreasonable. The cost to prepare a bid is typically $2-3 \%$ of the cost of the project to a bidder. On many occasions, bidders make last-minute adjustments in light of new information.
} 
Table 3 Probit regression results for probability of bidding

All regressions include a constant term and 11 monthly dummy variables and 7 year dummies. In the full sample we have included seven project component share variables. Robust standard errors are in parentheses (clustered by firms). Marginal effects are reported * denotes statistical significance at the $10 \%$ level

** denotes statistical significance at the $5 \%$ level *** denotes statistical significance at the $1 \%$ level

\begin{tabular}{|c|c|c|}
\hline Independent variables & Asphalt projects & Bridge projects \\
\hline Number of plan holders & $\begin{array}{l}-.019 * * * \\
(.004)\end{array}$ & $\begin{array}{l}-.015^{* * *} \\
(.002)\end{array}$ \\
\hline Log of ECE & $\begin{array}{l}.023 * \\
(.013)\end{array}$ & $\begin{array}{l}-.011 \\
(.010)\end{array}$ \\
\hline $\begin{array}{l}\text { Log of number of project } \\
\text { components }\end{array}$ & $\begin{array}{l}-.049 * * \\
(.018)\end{array}$ & $\begin{array}{l}-.011 \\
(.014)\end{array}$ \\
\hline $\begin{array}{l}\text { Log of number of days to } \\
\text { complete the project }\end{array}$ & $\begin{array}{l}-.036^{* *} \\
(.015)\end{array}$ & $\begin{array}{l}.025^{* *} \\
(.013)\end{array}$ \\
\hline Large firm dummy & $\begin{array}{l}.193 * * \\
(.071)\end{array}$ & $\begin{array}{l}.124 * * \\
(.029)\end{array}$ \\
\hline $\begin{array}{l}\text { Difference between firm's current } \\
\text { and average utilization level }\end{array}$ & $\begin{array}{l}-.035 \\
(.039)\end{array}$ & $\begin{array}{l}-.084 * * \\
(.029)\end{array}$ \\
\hline Log of distance to project & $\begin{array}{l}-.065^{* * *} \\
(.011)\end{array}$ & $\begin{array}{l}-.036^{* * *} \\
(.008)\end{array}$ \\
\hline $\begin{array}{l}\text { Bidders with ongoing projects } \\
\text { in the same project county }\end{array}$ & $\begin{array}{l}.207 * * * \\
(.021)\end{array}$ & $\begin{array}{l}.106^{* *} \\
(.020)\end{array}$ \\
\hline $\begin{array}{l}\text { Rival's average past bidding } \\
\text { to plan holder ratio }\end{array}$ & $\begin{array}{l}.035 \\
(.097)\end{array}$ & $\begin{array}{l}.135 \\
(.081)\end{array}$ \\
\hline $\begin{array}{l}\text { Seasonally unadjusted } \\
\text { unemployment rate }\end{array}$ & $\begin{array}{l}.035 \\
(.033)\end{array}$ & $\begin{array}{l}-.059 * \\
(.024)\end{array}$ \\
\hline $\begin{array}{l}\text { Three month average of } \\
\text { the real volume of projects }\end{array}$ & $\begin{array}{l}-.083 \\
(.053)\end{array}$ & $\begin{array}{l}.013 \\
(.038)\end{array}$ \\
\hline $\begin{array}{l}\text { Three month average of } \\
\text { the number of building } \\
\text { permits }\end{array}$ & $\begin{array}{l}-.226 \\
(.138)\end{array}$ & $\begin{array}{l}.173 \\
(.120)\end{array}$ \\
\hline Number of obs. & 7,443 & 9,658 \\
\hline Wald $\chi^{2}$ & 370.49 & 443.34 \\
\hline
\end{tabular}

unobserved heterogeneities. We consider here as well the possibility that the standard errors may be underestimated. We report standard errors clustered by firms.

As for the other RHS variables, the number of bid components, the number of days to complete a project, and potential for synergies are significant in the sample of asphalt projects. With respect to the bridge projects, the number of bid components, capacity utilization, rival's past winning to bidding ratio, unemployment rate, and building permits are significant. We also observe that first-session losers bid more aggressively in common value auctions on the second day.

Ignoring entry effects, in the second part of Table 4 (columns (5) and (6)), we report on the estimate of the direct relationship between equilibrium bids $(b)$ and the number of potential bidders $(N)$. We run a fixed effects model controlling for unobserved 
Table 4 Regression results for log of bids with firm fixed effects

\begin{tabular}{|c|c|c|c|c|c|c|}
\hline \multirow[t]{2}{*}{ Independent variables } & \multicolumn{2}{|c|}{ Asphalt projects } & \multicolumn{2}{|c|}{ Bridge projects } & \multirow{2}{*}{$\begin{array}{l}\text { Asphalt } \\
\text { projects }\end{array}$} & \multirow{2}{*}{$\begin{array}{l}\begin{array}{l}\text { Bridge } \\
\text { projects }\end{array} \\
\log (N) \\
(6)\end{array}$} \\
\hline & $\begin{array}{l}\mathrm{E}[A] \text { from } \\
\text { probit } \\
\text { (1) }\end{array}$ & $\begin{array}{l}\mathrm{E}[A] \text { from } \\
\text { past history } \\
(2)\end{array}$ & $\begin{array}{l}\mathrm{E}[A] \text { from } \\
\text { probit } \\
(3)\end{array}$ & $\begin{array}{l}\mathrm{E}[A] \text { from } \\
\text { past history } \\
\text { (4) }\end{array}$ & & \\
\hline $\begin{array}{l}\text { Log of expected number } \\
\text { of bidders } E[n]\end{array}$ & $\begin{array}{l}-.052 * * \\
(.019)\end{array}$ & $\begin{array}{l}-.046^{* *} \\
(.016)\end{array}$ & $\begin{array}{l}-.023 \\
(.022)\end{array}$ & $\begin{array}{l}.002 \\
(.017)\end{array}$ & & \\
\hline $\begin{array}{l}\text { Log of number } \\
\text { of plan holders }\end{array}$ & & & & & $\begin{array}{l}-.050^{* * *} \\
(.015)\end{array}$ & $\begin{array}{l}-.002 \\
(.016)\end{array}$ \\
\hline $\log$ of ECE & $\begin{array}{l}.941 * * * \\
(.006)\end{array}$ & $\begin{array}{l}.941 * * * \\
(.006)\end{array}$ & $\begin{array}{l}.890 * * * \\
(.011)\end{array}$ & $\begin{array}{l}.890 * * * \\
(.011)\end{array}$ & $\begin{array}{l}.940 * * * \\
(.006)\end{array}$ & $\begin{array}{l}.890 * * * \\
(.011)\end{array}$ \\
\hline $\begin{array}{l}\text { Log of number of } \\
\text { project components }\end{array}$ & $\begin{array}{l}.048 * * * \\
(.012)\end{array}$ & $\begin{array}{l}.048 * * * \\
(.012)\end{array}$ & $\begin{array}{l}.143^{* * * *} \\
(.017)\end{array}$ & $\begin{array}{l}.144 * * * \\
(.017)\end{array}$ & $\begin{array}{l}.048^{* * *} \\
(.012)\end{array}$ & $\begin{array}{l}.144 * * * \\
(.017)\end{array}$ \\
\hline $\begin{array}{l}\text { Log of number of days } \\
\text { to complete the project }\end{array}$ & $\begin{array}{l}.024 * \\
(.011)\end{array}$ & $\begin{array}{l}.027 * * \\
(.011)\end{array}$ & $\begin{array}{l}.014 \\
(.009)\end{array}$ & $\begin{array}{l}.015 \\
(.009)\end{array}$ & $\begin{array}{l}.028 * * \\
(.011)\end{array}$ & $\begin{array}{l}.015 \\
(.009)\end{array}$ \\
\hline $\begin{array}{l}\text { Difference between firm's } \\
\text { current and average utilization }\end{array}$ & $\begin{array}{l}.020 \\
(.020)\end{array}$ & $\begin{array}{l}.019 \\
(.020)\end{array}$ & $\begin{array}{l}.037 * * \\
(.019)\end{array}$ & $\begin{array}{l}.038 * * \\
(.018)\end{array}$ & $\begin{array}{l}.017 \\
(.020)\end{array}$ & $\begin{array}{l}.038 * * \\
(.018)\end{array}$ \\
\hline Log of distance to project & $\begin{array}{l}.015 * * \\
(.005)\end{array}$ & $\begin{array}{l}.016 * * \\
(.005)\end{array}$ & $\begin{array}{l}.010 \\
(.005)\end{array}$ & $\begin{array}{l}.010 \\
(.005)\end{array}$ & $\begin{array}{l}.016 * * * \\
(.005)\end{array}$ & $\begin{array}{l}.010 * * \\
(.005)\end{array}$ \\
\hline $\begin{array}{l}\text { Bidders with ongoing projects } \\
\text { in the same project county }\end{array}$ & $\begin{array}{l}.007 \\
(.012)\end{array}$ & $\begin{array}{l}.004 \\
(.012)\end{array}$ & $\begin{array}{l}-.005 \\
(.012)\end{array}$ & $\begin{array}{l}-.005 \\
(.012)\end{array}$ & $\begin{array}{l}.004 \\
(.012)\end{array}$ & $\begin{array}{l}-.005 \\
(.012)\end{array}$ \\
\hline $\begin{array}{l}\text { Bidder with potential } \\
\text { synergies }\end{array}$ & $\begin{array}{l}.017 * \\
(.010)\end{array}$ & $\begin{array}{l}.017 * \\
(.010)\end{array}$ & $\begin{array}{l}-.012 \\
(.012)\end{array}$ & $\begin{array}{l}-.013 \\
(.012)\end{array}$ & $\begin{array}{l}.017 \\
(.010)\end{array}$ & $\begin{array}{l}-.013 \\
(.012)\end{array}$ \\
\hline $\begin{array}{l}\text { Bidder with no potential } \\
\text { synergies }\end{array}$ & $\begin{array}{l}-.002 \\
(.010)\end{array}$ & $\begin{array}{l}-.001 \\
(.010)\end{array}$ & $\begin{array}{l}-.027 * * \\
(.010)\end{array}$ & $\begin{array}{l}-.027 * * \\
(.010)\end{array}$ & $\begin{array}{l}-.001 \\
(.010)\end{array}$ & $\begin{array}{l}-.027 * * \\
(.010)\end{array}$ \\
\hline $\begin{array}{l}\text { Rival's past winning to } \\
\text { plan holder ratio }\end{array}$ & $\begin{array}{l}-.123 \\
(.090)\end{array}$ & $\begin{array}{l}-.100 \\
(.089)\end{array}$ & $\begin{array}{l}-.361^{* *} \\
(.145)\end{array}$ & $\begin{array}{l}-.362 * * \\
(.144)\end{array}$ & $\begin{array}{l}-.154^{*} \\
(.088)\end{array}$ & $\begin{array}{l}-.361 * * \\
(.146)\end{array}$ \\
\hline $\begin{array}{l}\text { Seasonally unadjusted } \\
\text { unemployment rate }\end{array}$ & $\begin{array}{l}-.008 \\
(.017)\end{array}$ & $\begin{array}{l}-.009 \\
(.016)\end{array}$ & $\begin{array}{l}-.035^{* *} \\
(.015)\end{array}$ & $\begin{array}{l}-.033 * * \\
(.015)\end{array}$ & $\begin{array}{l}-.009 \\
(.017)\end{array}$ & $\begin{array}{l}-.033 * * \\
(.015)\end{array}$ \\
\hline $\begin{array}{l}\text { Three month average of } \\
\text { the real volume of projects }\end{array}$ & $\begin{array}{l}.012 \\
(.026)\end{array}$ & $\begin{array}{l}.016 \\
(.025)\end{array}$ & $\begin{array}{l}.004 \\
(.028)\end{array}$ & $\begin{array}{l}.003 \\
(.028)\end{array}$ & $\begin{array}{l}.014 \\
(.025)\end{array}$ & $\begin{array}{l}.004 \\
(.028)\end{array}$ \\
\hline $\begin{array}{l}\text { Three month average of the } \\
\text { number of building permits }\end{array}$ & $\begin{array}{l}.100 \\
(.077)\end{array}$ & $\begin{array}{l}.107 \\
(.076)\end{array}$ & $\begin{array}{l}.345^{* * *} \\
(.086)\end{array}$ & $\begin{array}{l}.345^{* * *} \\
(.087)\end{array}$ & $\begin{array}{l}.108 \\
(.077)\end{array}$ & $\begin{array}{l}.344 * * * \\
(.087)\end{array}$ \\
\hline Number of obs. & 2,186 & & 2,383 & & 2,186 & 2,383 \\
\hline Adj. $R^{2}$ & .966 & & .965 & & .966 & .965 \\
\hline
\end{tabular}

All regressions include a constant term, 11 monthly dummy variables, seven annual dummy variables, and 24 project division dummy variables. Robust standard errors are in parentheses (clustered by firms)

* Denotes statistical significance at the $10 \%$ level

** Denotes statistical significance at the $5 \%$ level

*** Denotes statistical significance at the $1 \%$ level 
bidder heterogeneities. We use log of bids as our dependent variable, but use the log of number of plan holders rather than log of expected number of bidders. The results suggest that, the competitive effect is significant in asphalt projects. As potential bidders increase, bids become more aggressive. A comparison of the estimated effects from columns 1, 2 and 5 for asphalt projects and 3, 4 and 6 for bridge work suggest the lack of significant entry effects across specifications. This was expected in the common value case according to Lemma 2 but not in the private value case where the competitive effect seems consistently dominant.

\section{Open Questions and Policy Implications}

We present the equilibrium to a procurement auction for projects that can have a mixture of private and unknown common cost components. Bidders learn the number of potential bidders in the auction, as it becomes publicly known which companies hold plans for the projects. However, as not all plan holders actually bid, bids are prepared and submitted without bidders knowing the number of rivals that they face. Our focus is on how the nature of the project-whether largely composed of private cost uncertainty, or common cost uncertainty-affects bidding under numbers uncertainty and how an increase in the number of potential bidders affects bidding behavior in these two polar cases.

The theoretical model indicates that in pure private value settings an increase in the number of plan holders has a direct beneficial effect on bidding, leading to lower costs to the procuring agency (this is the competition effect). However, as a result of lower profit margins for the winners of procurement auctions, the incentive to go through the costly bid preparation process is diminished, which depresses the number of bids submitted (this is the entry effect). This latter effect can be sufficiently large to offset the initial beneficial effect of increasing the number of potential bidders - so that it may possibly be advisable in order to keep the cost of procurement down to restrict the number of potential bidders.

In the common value setting, due to winner's curse considerations, the entry effect itself is ambiguous. As such, the problem of a negative cost impact of increased potential competition may be more subtle.

Using data from procurement auctions run by the Texas Department of Transportation, we conduct an empirical investigation of actual bidding behavior in procurement auctions. As common cost components and private cost components differ systematically across the types of projects that are auctioned, we are able to differentiate between these two paradigms in our empirical estimation. Our analysis reveals that encouraging potential entry is largely beneficial for the state in auctions with predominantly private costs (asphalt paving). In auctions that exhibit common cost uncertainty (bridge repairs) there is no evidence of a significant competitive effect.

Given the theoretical and real concerns about possible adverse effects of increasing potential competition in procurement auctions, the preliminary empirical investigations and the theoretical model suggest an urgent need for a better understanding of the issue along several dimensions: First, a better understanding is needed of how prone procurement auctions are to such adverse effects-possibly determining systematic 
differences between common and private cost auctions-both in theory, but, more importantly, also in practice. Second, in instances where increased potential competition is expected to have adverse effects, studies are needed of how these effects can best be ameliorated. This raises the issue of restricting entry into procurement auctions. However, the potential benefits of restricting competition must be quantified in order to be able to contrast them to possible costs, as the practice may be fraught with concerns regarding equity across potential bidders, as well as concerns of possible corruption.

\section{Appendix}

See Table 5 .

Table 5 Regression variables

\begin{tabular}{ll}
\hline Independent variable & $\begin{array}{l}\text { Description and construction of the } \\
\text { independent variable }\end{array}$
\end{tabular}

Log of bids

Relative bid

Bid dummy variable

Number of bidders

Log number of bidders

Log of expected number of bidders

Number of plan holders

Log number of plan holders

Log of ECE

Log number of days to complete project

Difference between firm's current utilization and average utilization
Log value of bids

Bid divided by the ECE

Bid dummy variable takes the value of one if a plan holder submits a bid. Else it is equal to zero

The number of bidders in an auction

The $\log$ value of number of bidders

The expected number of bidders is calculated by summing the probabilities predicted from the probit model that a bidder participate for a given auction. Then we take the $\log$ value of the expected number of bidders

Number of plan holders in an auction

Log value of number of plan holders

This is the log value of the ECE

Log value of days to complete the project assigned by TxDOT

The utilization rate is the current project backlog of a firm divided by the maximum backlog of that firm during the sample period. For firms that have never won a contract, the utilization rate is set to zero. Data from the year 1998 are used to construct a set of initial starting values for the capacity utilization variable. The 1998:08-1999:12 data is not used in the empirical models. The backlog variable is constructed as follows: For each awarded project, TxDOT pays the monthly work completed amount. A contract backlog is constructed in each month by summing across the remaining value of all existing contracts in Texas for a firm. As projects are completed, the backlog of a firm goes to zero unless new contracts are won. Then we take the average capacity rate for firm for the entire sample and calculate the difference between firm's current utilization and average utilization 
Table 5 continued

\begin{tabular}{ll}
\hline Independent variable & $\begin{array}{l}\text { Description and construction of the } \\
\text { independent variable }\end{array}$
\end{tabular}

Distance to the project location

Average rivals bidding to plan holder ratio

Average rivals winning to plan holder ratio

Closest rival's distance to the project location

Rivals minimum backlog

Large firm dummy variable

Seasonally unadjusted unemployment rate

Three month average of the real volume of projects

Three-month average of the number of building permits

Log number of bid components

Bid item shares compared to ECE
The logarithm of the distance to a project is constructed as the distance between the county the project is located in and the distance to the firm's location. The county location is measured by the longitude and latitude at the centroid of the 'county seat'

The measure of rivals' past average success $(A R B P)$ in auctions is constructed as the average across rivals of the ratio of past bids to the past number of plans held. It captures the probability of a rival's bidding given that it is a plan holder

The measure of rivals' past average success $(A R W P)$ in auctions is constructed as the average across rivals of the ratio of past wins to the past number of plans held. This variable incorporates two aspects of past rival bidding behavior. It incorporates both the probability of a rival's bidding given that it is a plan holder and the probability that the rival wins an auction given that it bid. These probabilities are updated monthly using the complete set of bidding data in Texas. The probabilities are initialized using data from 1998

This variable measures the distance (log of miles) between the project location and the closest rival

This variable contains the minimum backlog of the rival firms in an auction $[\log ($ backlog+1) $]$. See the capacity utilization variable discussion above for a detailed explanation of how the backlog variable is constructed

This is a dummy variable that identifies the firm size by the number of past wins. For asphalt projects the large firm dummy variable takes the value 1 when a firm has won at least 34 and for bridge projects this number is at least 20 wins

The monthly state-level unemployment rate in Texas from the US Bureau of Labor Statistics

This variable measures the three-month moving average of the real volume of all projects in Texas. The real volume of projects is constructed by adding the ECE across projects that were up for bid in a month for Texas and deflating the current value by the PPI. Then we divide it by the average of the real volume for each state to calculate the relative real volume

This variable measures the three-month moving average of the relative number of building permits for Texas. The data come from the US Bureau of Economic Analysis This is the total amount of bid items (project components) in a project described by TxDOT

All bid items are categorized by TxDOT according to Texas Standard Specification (2004) guide lines. We sum the total dollar value of these bid components according to these categories for each auction. Then we calculate the share of each category as a ratio of ECE. The main categories are asphalt (surface), bridge (structures), earth work, maintenance, miscellaneous, subgrade, and traffic work 
Table 5 continued

\begin{tabular}{|c|c|}
\hline Independent variable & $\begin{array}{l}\text { Description and construction of the } \\
\text { independent variable }\end{array}$ \\
\hline Monthly dummy variables & $\begin{array}{l}\text { Monthly dummy variables are a set of } 12 \text { variables that } \\
\text { control for the months of the year. The omitted month is } \\
\text { January }\end{array}$ \\
\hline Project division dummy variable & $\begin{array}{l}\text { TXDOT has divided TX into } 25 \text { divisions. The project } \\
\text { location dummy variables identify the } 25 \text { divisions from } \\
\text { which we draw data for our analysis }\end{array}$ \\
\hline $\begin{array}{l}\text { Bidders with ongoing projects in } \\
\text { same county }\end{array}$ & $\begin{array}{l}\text { This dummy variable identifies bidders when they are } \\
\text { bidding on projects where they have an ongoing project in } \\
\text { the same county }\end{array}$ \\
\hline Bidder with potential synergies & $\begin{array}{l}\text { This dummy variable identifies a first-session winning } \\
\text { bidder that is bidding in the second session on given } \\
\text { month }\end{array}$ \\
\hline Bidder with no potential synergies & $\begin{array}{l}\text { This dummy variable identifies a first-session losing bidder } \\
\text { that is bidding in the second session on given month }\end{array}$ \\
\hline
\end{tabular}

Note: All data come from the Texas Department of Transportation except the state-level unemployment and building permits data that come from the Bureau of Labor Statistics and the Bureau of Economic Analysis

\section{References}

Bajari, P., \& Ye, L. (2003). Deciding between competition and collusion. Review of Economics and Statistics, 85(4), 971-989.

De Silva, D. G. (2005). Synergies in recurring procurement auctions: An empirical investigation. Economic Inquiry, 43(1), 55-66.

De Silva, D. G., Dunne, T., Kankanamge, A., \& Kosmopoulou, G. (2008). The impact of public information on bidding in highway procurement auctions. European Economic Review, 52, 150-181.

De Silva, D. G., Dunne, T., \& Kosmopoulou, G. (2002). Sequential bidding in auctions of construction contracts. Economics Letters, 76(2), 239-244.

De Silva, D. G., Dunne, T., \& Kosmopoulou, G. (2003). An empirical analysis of entrant and incumbent bidding in road construction auctions. Journal of Industrial Economics, 51(3), 295-316.

De Silva, D. G., Jeitschko, T. D., \& Kosmopoulou, G. (2005). Stochastic synergies in sequential auctions. International Journal of Industrial Organization, 23(3-4), 183-201.

De Silva, D. G., Kosmopoulou, G., \& Lamarche, C. (2009). The effect of information on the bidding and survival of entrants in procurement auctions. Journal of Public Economics, 93, 56-72.

Deltas, G., \& Jeitschko, T. D. (2007). Auction hosting site pricing and market equilibrium with endogenous bidder and seller participation. International Journal of Industrial Organization, 25(6), 1190-1212.

Engelbrecht-Wiggans, R. (1987). On optimal reservation prices in auctions. Management Science, 33(6), 763-770.

Goeree, J. K., \& Offerman, T. (2003). Competitive bidding in auctions with private and common values. Economic Journal, 113(489), 598-613.

Harstad, R. M. (1990). Alternative common-value auction procedures: Revenue comparisons with free entry. Journal of Political Economy, 98, 421-429.

Hendricks, K., Pinkse, J., \& Porter, R. H. (2003). Empirical implications of equilibrium bidding in first-price, symmetric, common value auctions. Review of Economic Studies, 70(1), 115-145.

Hong, H., \& Shum, M. (2002). Increasing competition and the winner's curse: Evidence form procurement. Review of Economic Studies, 69, 871-898.

Jofre-Bonet, M., \& Pesendorfer, M. (2003). Estimation of a dynamic auction game. Econometrica, 71(5), 1443-1489.

Krishna, V. (2002). Auction theory. London: Academic Press.

Levin, D., \& Smith, J. L. (1994). Equilibrium in auctions with entry. American Economic Review, 84(3), 585-599. 
Li, T., \& Zheng, X. (2008). Entry and competition effects in first-price auctions: Theory and evidence from procurement auctions. Review of Economic Studies (in press).

Marmer, V., Shneyerov, A. \& Xu, P. (2007). What model for entry in first-price auctions? A nonparametric approach. Working paper, University of British Columbia and Concordia University.

Menezes, F. M., \& Monteiro, P. K. (2000). Auctions with endogenous participation. Review of Economic Design, 5(1), 71-89.

Moreno, D., \& Wooders, J. (2008). Auctions with heterogeneous entry costs. Mimeo: University of Arizona.

Moulton, B. R. (1990). An Illustration of a pitfall in estimating the effects of aggregate variables on micro units. Review of Economics and Statistics, 72(2), 334-338.

TxDOT Specifications. http://www.dot.state.tx.us/business/specifications.htm.

Wolfstetter, E. (1999). Topics in microeconomics: Industrial organization, auctions, and incentives. Cambridge: Cambridge University Press.

Wilson, R. B. (1992). Strategic models of entry deterrence. In R. Aumann \& S. Hart (Eds.), Handbook of game theory (Vol. 1, Chap. 10, pp. 305-329). Amsterdam: Elsevier. 